\title{
IF E-BUSINESS IS DIFFERENT, THEN SO IS RESEARCH IN E-BUSINESS
}

\author{
ROGER CLARKE \\ Xamax Consultancy Pty Ltd, Australian National University
}

\begin{abstract}
Information systems research is challenging enough, but information systems research in the e-business domain presents even greater difficulties, because its characteristics are in direct conflict with the implicit assumptions underlying most academic research. Approaches are suggested whereby relevant research into e-business can be undertaken. The delivery of real-world value while achieving sufficient rigour to satisfy the guardians of academic standards will, however, remain problematical.
\end{abstract}

\section{INTRODUCTION}

Electronic commerce burst onto the scene in the early 1990s (see, for example, Clarke 1993). Of the many disciplines whose techniques can be brought to bear on electronic commerce, Information Systems is an important one (Clarke 1990, 1992). Practitioners of the Information Systems discipline, in searching for appropriate ways to undertake research in the domain, have been confronted by many challenges. This paper's purpose is to identify and discuss those challenges, and propose appropriate ways of conducting research.

The paper commences by reviewing the nature of scientific research, and the assumptions that are implicit in it. It contrasts this against the rather different assumptions inherent in two primary alternative approaches, interpretivism and engineering research. The characteristics of e-business are delineated, and a description is provided of the expectations that real-world audiences have of research in the e-business domain.

The original version of this chapter was revised: The copyright line was incorrect. This has been corrected. The Erratum to this chapter is available at DOI: 10.1007/978-0-387-35692-1_36 
Preliminary results of an assessment of published e-business research are presented, and substantial weaknesses in the body of work undertaken to date are identified. Suggestions are made as to how I.S. practitioners can go about addressing the challenges, and improving the quality of research into e-business.

\section{IMPLICIT ASSUMPTIONS IN SCIENTIFIC RESEARCH}

The nature of scientific research is the subject of a large literature. For a discussion and a substantial collection of references, see Clarke (2000a). This section confines itself to a few key observations that enable development of the argument pursued in the rest of the paper.

Following Popper $(1959,1968)$, a theory is scientific if and only if it generates inferences that are refutable by reference to the real world. Following in particular Kuhn (1962), key features of the process of scientific research are as follows:

- $\quad$ it investigates 'research questions' within a 'domain';

- it is driven by theories that:

- $\quad$ are founded on axioms, which are unchanging;

- $\quad$ comprise trees of deductive inference; and

- $\quad$ enable the generation of 'hypotheses' that are explicit, unambiguous and refutable;

- research design has the following objectives:

- $\quad$ to empirically test the hypotheses. This involves undertaking observation and measurement of the real world, in such a manner that the hypotheses, if false, will be shown to be so;

- to exercise control over confounding variables; and

- $\quad$ to be sufficiently well-documented to be replicable;

- its outcomes:

- $\quad$ in most cases, refine, extend or articulate the theory;

- $\quad$ in some cases, are not entirely consistent with the theory;

- $\quad$ result in the gradual accumulation of 'anomalies'; and

- $\quad$ enable, from time to time, a more general theory to be formulated, which accommodates the anomalies, and results in a 'paradigm shift'.

The following terms are used in this paper with the following meanings: 
- 'research technique' refers to a specific means, approach or tool-and-itsuse, whereby data is gathered and analysed, and inferences are drawn;

- 'research method' refers to the manner in which a particular project is undertaken. It comprises one or more research techniques; and

- 'research methodology' refers to the study of research methods. It is a singular that does not admit of a plural.

Inherent in scientific research are some meta-physical assumptions that are less frequently expressed, but that are nonetheless critical, in particular:

- there is a 'real world';

- the phenomena in that real world are stable;

- data can be gathered by observing the real world;

- such data are factual, truthful and unambiguous;

- the domain of study is unaffected by the research;

- the domain of study is unaffected by the researcher; and

- the language in which theory is expressed is unambiguous, and contains no value judgements.

From these assumptions, combined with my observation of the application of the scientific method within the information systems discipline, I suggest that the following attitudes are inherent:

- rigour is paramount, in order that theories can be built;

- where relevance conflicts with rigour, relevance has to be a secondary consideration;

- to be cohesive, a body of theory needs to exist within a single clearlydefined discipline. It may draw on reference disciplines for axioms, but should not be inherently multi-disciplinary;

- instability of the phenomena within a research domain is highly inconvenient;

- perturbability of the phenomena by research and the presence of researchers is also highly inconvenient;

- the rapid accumulation of anomalies is also highly inconvenient, and is a sign of an insufficiently mature body of theory.

\section{ALTERNATIVES TO CONVENTIONAL SCIENTISM}

There are substantial advantages in the scientific approach. At least when applied to social phenomena, however, its inherent assumptions create difficulties. As the information systems discipline has matured, it has increasingly questioned those assumptions, and the techniques associated with scientistic research (e.g. Klein \& Lyytinen 1985). 
An alternative approach that was dominant in western thought for more than a millenium is to focus on the ideal world of thought, and regard the physical world as an imperfect and temporary inconvenience. Given the argument developed below concerning the needs of the audiences for ebusiness research, however, it would clearly not be satisfactory to resort to contemplation alone, and abandon the empirical orientation and the preference for theories to relate to the imperfect physical world.

Interpretivism has provided an alternative basis for research, and during the last two decades has become well-accepted in the information systems discipline. It embodies alternative assumptions, which run counter to those of the scientific approach. In particular, these include the following:

- the observer's perspective is a factor:

- $\quad$ in the selection and formulation of theory;

- $\quad$ in the formulation of hypotheses;

- $\quad$ in choices made in the research design process;

- $\quad$ in the selectiveness of observation; and

- $\quad$ in the process of observation;

scientific objectivity is infeasible:

- $\quad$ in general; and

- $\quad$ especially where the domain includes entities that exercise what appears to be free will.

A further alternative, usefully described as 'engineering' research, focuses away from the social setting, and towards artefacts. These may be designed and constructed, or protoyped and trialled, in order to enable effective interventions to be undertaken in a particular domain; or existing artefacts may be experimented with, in order to identify the limits of their applicability, effectiveness or usefulness.

\section{CHARACTERISTICS OF E-BUSINESS}

In order to assess the applicability of the various research approaches, it is necessary to identify key features of the e-business domain. This in turn requires working definitions for the main terms.

Since 1993, I have used a series of broad definitions to define the scope of the domain (Clarke 1997a). By 'electronic commerce' and 'e-commerce', I mean the conduct of trading with the assistance of telecommunications and telecommunications-based tools. Correspondingly, 'electronic business' or 'ebusiness' is the conduct of business generally, with the assistance of telecommunications and telecommunications-based tools. e-business 
therefore encompasses a wide range of activities such as e-commerce (Clarke 1993), e-publishing (Clarke 1997b) and electronic services delivery (Clarke 1999). Its scope extends across the business activities of all categories of organisations and individuals, whether undertaken for profit, or as a service to some community.

In recent years, there has been a trend within the U.S.A. to adopt a much narrower interpretation of the term 'e-business'. This restricts it to business enterprises alone, and focuses on their internal processes. See, for example, Alter et al. (2001). Such narrowness seems to have been inspired by the belated adoption of a trade-marked semi-graphical representation of 'ebusiness' by a major information technology provider. It would be a serious disservice to the discipline if such a narrow and industry-driven interpretation were to become mainstream.

The terms e-commerce and e-business have been applied retrospectively to the use of electronic data interchange (EDI) and value-added networks (VANs) and various forms of on-line services, which commenced as early as the late 1960s, and became mainstream during the 1980s. The currency of the terms dates, however, from early-mid 1990s, reflecting the explosion of public use of the Internet, and of key services enabled by the Internet, particularly email and the World Wide Web.

The domain has become considerably segmented during its first decade, in particular through the discovery that significantly different factors are at work in the various relationships among businesses, governments, consumers and citizens, giving rise to a $3 \times 3$ (or possibly $4 \times 4$ ) matrix. Of these 9-12 contexts, only B2B and B2C have been subjected to intensive study, although $\mathrm{C} 2 \mathrm{C}$ is now attracting greater attention.

Some key features of e-business distinguish it from most other domains that have been of interest to I.S. researchers. It is new and exciting, and with that comes a lack of circumspection, a very high level of 'marketing hype', and downright exaggeration. This has been a key factor in the casino mentality of the late 1990s, in which dot.com fervor turned investors into gamblers, and encouraged an unworldly belief in the economics of business having been re-written overnight.

The newness of the domain has meant that no one was well prepared to participate in it, much less conduct research into it. Awareness and then reflection necessarily precede understanding, general principles take time to be extracted, courses have to be devised, and most of the pioneers are by definition too busy doing it to explain it or train people in it. As a result, a great deal of the early development and application of new technologies has a high 'turkey-factor', and the opportunity for latecomers to apply '20-20 hindsight' is enormous. 
Associated with this is the complete lack of stability in the phenomena within the domain. Technologies keep being re-defined. Perceptions of the purposes and potentials of the technologies change rapidly. Participant behaviour is dependent on perceptions at the time a technology or its application is first experienced, but is subject to learning, which in some cases is very brisk. The perceptions of the needs that are being addressed migrates. Technologies diverge, then converge, and products re-combine. Underlying all of this is a high degree of terminological confusion, with technologists and thoughtful observers struggling to apply existing words and phrases, and invent new ones, all the time having their contributions undermined by marketers whose understanding of the technologies is vastly exceeded by their enthusiasm, their imprecision, and their avarice.

A further crucial aspect of e-business is its reach and borderlessness. Beyond the hype, this means to researchers that there are some significant additional confounding variables. One of these is the difficulty of defining populations, population segments, and sampling frames. Another is the inability to rely any longer on geographical extent as a proxy for cultural commonality. Suddenly, key cultural factors have to be identified and controlled for, because, if due attention is not paid to the cultural setting(s), the results will be patent nonsense. This is an enormous challenge, given the utter inadequacy of theories of cultural definition and behaviour, and the lack of clarity even about the dimensions of what 'culture' means in the contexts of business services and electronic participation.

\section{THE PRACTICE OF E-BUSINESS RESEARCH}

Despite the many challenges identified above, journal editors encourage submission of papers on e-business topics (e.g. Zwass 1996), and stimulate special issues. Many I.S. academics have grasped the nettle, and conducted research into many different aspects of e-business. An important question that arises is: what are the audiences that are expected to read the results of this research?

A great deal of research in the I.S. discipline, as in many others, is conducted primarily for the purpose of publication in research journals and presentation at research conferences, and hence as a means of progression within the academic profession. The audience is therefore other I.S. researchers, in particular the gatekeepers, i.e. editors, program chairs, referees, and assessors of research grant applications (a group that is conventionally, but rather misleadingly, referred to as 'one's peers').

There are many further categories of people, however, who are interested in the outcomes of research into e-business. Among those desperate for 
insights are the developers of new technologies; the professionals, managers and individual workers who apply them; and process specialists who devise approaches whereby the technologies can be effectively applied within organisational contexts. Investors are equally eager for information that will enable them to select among the plethora of bright ideas that are in need of capital. A final category of real-world audience is policy analysts, particularly within government and applied social research organisations, but also in associations of corporations, consumers, citizens and workers, and in large corporations.

Those real-world audiences have interests very different from the research community. Their focus is on 'proof-of-concept' prototyping, the development of products and services, demonstration applications, understanding about users' reactions to them, and appreciation of how their features can be communicated to prospects. Particularly once they have developed a significant capital and/or psychic investment, they have a strong preference for the 'right' answers, or at least not the 'wrong' ones. They are uninterested in researchers whose choice of topic, hypotheses, method, analysis and timetable, are dictated primarily by the demands of journal editors.

This leads to a need to analyse several aspects of research that are often left to one side by academics. One of those aspects is the motivation for the research activity. The following alternatives need to be distinguished:

- 'pure research'. This is typified by the wish to conquer something "because it's there". More prosaically, research of this kind is undertaken with the primary intention of contributing to abstract, theoretical understanding. It is the approach that is most acceptable for academic journals and research conferences;

- 'applied research'. This can be depicted as "I have a hammer, so go and find me a nail". This still falls within the realm of academic research, because it can be reasonably strongly theory-driven. It is more attractive to businessmen and practitioners than pure research, but still falls short of their needs. For example, the cluster of techniques referred to as operations research has long been subject to the deprecatory description of being 'a tool-kit looking for a problem to solve';

- 'instrumentalist research'. The catchcry of this approach is "I have a problem, so go and find me a solution". This provides a good fit to the interests of real-world audiences. On the other hand, research driven by this motivation is very difficult to report on in formal research outlets. It is not sufficiently theory-driven, and is very likely, in its search for answers, to cross boundaries into multiple disciplines.

Another distinction that needs to be drawn might be referred to as the focus of the research. The following alternatives exist: 
- the technology or process, which is oriented towards the question 'what is this thing?';

- applications of the technology or process, which involves the question 'what do I do with it?';

- adoption and impediments to adoption, which asks 'how do I make sure it gets used?';

- impact, which is interested in 'what will its first-order effects be?'; and

- implications, which is concerned with 'what will its second-order effects be?'.

Activities can also be differentiated according to the nature of the research outcomes. The alternative forms they may be in are as follows:

- descriptive outcomes, providing a depiction of a behaviour or a domain;

- $\quad$ explanatory outcomes, providing either:

- $\quad$ statistical correlations among factors that appear to be associated with particular behaviours; or

- $\quad$ systemic explanation of how behaviours arise, possibly extending to an ascription of the causes of occurrences in the domain; predictive outcomes, which offers answers to such questions as 'what behaviour will arise, and how?', 'what occurrences will arise within the domain?', and 'what effect will a particular intervention have?'; and - normative outcomes, which state which interventions are likely to achieve a desired outcome, subject to various environmental circumstances.

The rigorous research that is attractive to journal editors is most commonly explanatory (especially where it involves statistical correlation) or perhaps predictive in nature. Normative outcomes must by their nature involve discussion of, and perhaps even adoption of, value-judgements. They are highly desirable for real-world audiences, but anathema to journal editors.

Keen (1980) and others have drawn attention to the eternal tension between relevance and rigour. Associated with rigour are independence from sponsors' interests, through pure research motivation, explanatory outcomes, and quantitative data, with a preference for the ratio scales that enable the tools of statistical analysis to be brought to bear. Associated with relevance, on the other hand, are instrumentalist motivation, predictive and normative outcomes, and whatever data is collectable.

Researchers in the e-business domain are confronted by enormous challenges. Those who value publishability in major academic journals well 
above the impact of their work on practitioners are well-advised to conduct their research in other, less dynamic domains.

\section{WHAT E-BUSINESS RESEARCH IS PUBLISHED?}

Despite the serious challenges, some e-business is being published, and not only in refereed proceedings such as those of the premier annual event in Bled (now in its 14th year), but also in journals.

A colleague and myself have been cataloguing e-business research publications in the primary information systems journals. Assessment is not yet complete of the small number of specialist EC journals, primarily the 18 issues of the International Journal of Electronic Commerce since mid-1996, Electronic Markets (in particular the 10 issues since February 1999) and the 6 volumes of Journal of Electronic Commerce Research since February 2000 .

Cataloguing of 5 major research journals (MISQ, ISR, Information \& Management, Decision Science and JMIS), and of the primary 'emergent issues' journal (Commun. ACM) has been completed. The period assessed is that since the explosion of e-commerce in about 1993, until late 2000. The following conclusions can be drawn:

- 37 e-business articles were published in the 5 selected research journals and 38 in the leading 'issues' journal;

- in the issues journal, 25 of the 38 were theoretical-only. Of the 13 that included empirical work, the research technique used comprised 1 survey, 8 case studies, and 4 field studies;

- in the 5 research journals, 10 of the 37 were theoretical-only. In the 27 papers reporting on empirical research, 11 involved surveys, 3 interviews, 14 case studies, and only 1 a field study.

EDI was the topic in 16 of the 37 research articles, but not a single one of the 38 in the issues journal. EDI is a technology of long standing, relatively stable, well-understood, and used by many organisations. It therefore qualifies as a suitable topic for research and publication in learned journals. It is utterly atypical of e-business, however, because it is batch-oriented and not interactive, and highly structured rather than open-ended. The results are unlikely to be of high value to practitioners in coping with the problems they face. Reflecting this change in priorities, the leading specialist international conference, held in Bled, Slovenia each year, was an EDI conference 198893, in transition 1994-95, but has been an e-commerce conference since 1996. 
In short, the evidence from this limited study suggests that rigour continues to heavily dominate relevance in the selection of research topics for publication in refereed journals.

\section{WHY E-BUSINESS RESEARCH IS MOSTLY OF LOW QUALITY}

The author has reviewed a great deal of research in the e-business domain, generally as a member of the community, and as a referee and conference program chair and member. This section explains why he considers that most e-business research is not of high quality, with little of it satisfying journal editors, little of it satisfying non-academic audiences, and almost none of it satisfying both.

The first observation that has to be made is that good research in any social domain that is multi-segmented, young and changing rapidly, is extremely difficult to devise and to implement. Established theories are in short supply; terminology is distorted; such source data as is available is tainted; models of participant behaviour are lacking; the researcher is frequently also a participant and even a protagonist; the populations being studied are poor survey-subjects; the staleness factor makes publication urgent; and the strong demand that exists for populist reports stimulates premature release.

In addition, the management of research presents challenges that are particularly acute in the context of e-business. These include:

- $\quad$ insufficient relevance to attract industry funding, or (at the other extreme) excessive influence by the sponsor over topics, techniques and outcomes;

- $\quad$ inadequate resourcing to achieve the aims by supporting all of:

- $\quad$ researcher time;

- $\quad$ supervisor time;

- $\quad$ travel costs;

- $\quad$ infrastructure costs;

- $\quad$ support staffing; and

- $\quad$ host-institution levies;

- inadequate timeframe, arising from such sources as:

- slow cycles of grant request, grant approval, candidate search, and candidate preparation; and 
- the need for time-variant phenomena to be subjected to longitudinal study, over a period longer than a candidature or research assistantship.

Some of the low quality in e-business research, however, is not excusable on the grounds discussed above. One recurrent poor research practice is the unquestioning application of convenience reference theories such as Hofstede's cultural factors theory, Rogers' innovation diffusion theory, and transaction cost theory. These have some applicability to e-business, but they suffer serious weaknesses, yet are commonly applied without any assessment of their relevance.

There are also problems with the selection and implementation of reesearch techniques. Semi-structured interviews frequently masquerade as case studies, without the combination of depth and breadth that triangulation demands, and that is needed for any validity to be claimed. Meanwhile, consultancy work poses as [action] research.

Many problems are routinely evident in reports on surveys. These include:

- $\quad$ surveys are used as the sole technique even when:

in-depth information is needed as well; and

in-depth information is needed instead;

- $\quad$ effort is invested merely in questionnaire design, with the many other aspects of survey design short-changed. Particular problems include the following:

- survey objectives are ill-defined;

- the population, the sampling frame and the sample are not clearly defined;

- $\quad$ population stratification / segmentation is overlooked or oversimplified, in deference to the need to have enough responses to be statistically meaningful. In particular:

- the mythical 'SME' is not classified into micro, small and medium-sized enterprises, nor divided into independent, loosely-controlled subsidiary and closely-controlled subsidiary categories;

- no distinction is made among large single-function companies, cohesive multi-divisional business enterprises, conglomerates of operationally independent subsidiaries, multinational corporations, and virtual business enterprises; 
- government agencies are not differentiated according to the various functions that they perform (in particular, service delivery, regulation and policy-formation); and

- non-profit/not-for-profit organisations are not differentiated by function;

- convenience samples are used with no apology and even no recognition, including proxies (such as the researcher's Masters class) instead of principals, and whoever responds to an emailed request;

- no account is taken of the principal-agent problem, i.e. the assumption is made that an employee speaks reliably on behalf of their employer;

- no account is taken of the simple fact that what people say and what people do are not the same thing;

- data analysis pays attention to the syntax (statistical correctness) but overlooks the semantics. In particular:

- $\quad$ enormous respondent diversity is inadequately controlled;

- questionnaires use highly ambiguous terminology that is differentially interpreted by respondents, without control being exercised;

- long lists of 'Likert or not' data masquerade as information, without control being exercised over respondent comprehension, boredom, and the ease of providing semi-random answers;

- the low response-rates and response-counts that are inevitable from over-surveyed and uninterested populations are routinely ignored; and

- the sources and impact of non-response bias are inadequately considered.

Some research practices go beyond the question of quality to that of morality. As a contribution to a panel session at ICIS'2000, Clarke (2000b) identified a raft of ethical issues that arise in relation to the submission of papers arising from research, including matters relating to sponsorship, authorship, 'school of manoeuvres, the depiction of the research method used, plagiarism, references and citations, depiction of the research's significance, consideration of the research's implications, economic factors, 'political correctness', and choice of submission venue(s). 


\section{TENABLE RESEARCH TECHNIQUES FOR E- BUSINESS}

This paper has portrayed a grim picture. It has identified many difficulties presented by e-business, and drawn attention to a litany of problems that arise even in conventional I.S. research, and which are yet more challenging to master in a new and dynamic context. This section sets out to re-build some confidence in the conduct of research in e-business, but on new terms. It is intended to complement more general guides regarding the selection of research techniques, such as Galliers (1992).

The first observation is that there is progress. As evidenced in the section above on e-business research publications in journals, there is an e-business research literature, however limited; and hence the domain is no longer entirely 'virgin territory' or 'a green-fields site'.

In a relatively young discipline, focussing on a very new domain, nonempirical techniques have a considerable amount to offer. One is reviews of existing literatures, within the discipline, in cognate disciplines, and in less familiar reference disciplines. Conceptual research (often referred to as 'armchair reasoning', like this paper) can provide impetus to research, and assist empirical work to avoid weaknesses.

Other non-empirical techniques that can offer assistance in particular circumstances include the following:

- scenario-building;

- futurism, especially Delphi rounds;

- game- or role-playing; and

- simulation.

Among the scientific techniques, laboratory experimentation, and where feasible field experimentation and quasi-experimental designs offer prospects.

Interpretivist techniques that are directly relevant to various problems that instrumentalist e-business research can address include:

- descriptive/interpretive work;

- grounded theory;

- focus groups;

- action research; and

- ethnographic research.

A number of relevant techniques lie at the boundary of the scientific and interpretivist research approaches, and are used within both traditions. These include:

- secondary research, drawing on existing sources, including metaanalysis; 
- questionnaire-based surveys, provided that their limitations are taken into account and acknowledged, and their weaknesses are addressed through the use of complementary techniques;

- interview-based surveys;

- case studies, but provided that proper attention is paid to the deep and multi-sourced nature of the technique; and

- field studies.

Finally, engineering techniques offer a great deal to some kinds of investigations, including:

construction of an artefact, including:

- $\quad$ conception (based on a body of theory);

- $\quad$ design / creation / prototyping / testing; and

- application;

- destruction of an artefact, including:

- $\quad$ testing (but on real people, not proxies); and

- application.

The following suggestions are made about particularly suitable research techniques:

- Field Study through Observation. e-business is characterised by a lack of theory and models. There is a need for foundation work to be performed, relatively free from the constraints of theory. Several techniques in the interpretivist tradition lend themselves to this purpose;

- Case Studies. Where a body of theory is available, it can be brought to bear through the combination of documentary research, interviews, small, targeted surveys and observation, in order to achieve triangulation. Care must still be taken to reflect the body of knowledge that exists on the scope for, and limitations of, the case study method;

- Laboratory Experimentation. Because many artefacts are very new, and the impact and implications of the intervention, and of particular features of it, are uncertain, there is scope for the development of prototypes, and the laboratory use of prototypes and alpha- and betaversions of new products, initially perhaps by proxies, but primarily by members of the target population;

- Field Experimentation. Particularly in such areas as user interface and the comprehensibility and usefulness of new functionality, opportunities exist for field trials to be undertaken in large 
organisations, with metrication designed in, and with experimental and control groups in different locations;

- Surveys. Although their limitations are substantial, circumstances exist in which responses to questions can be reliably and usefully gained from tightly-defined and -segmented populations.

Finally, the observation is offered that, of all of the aspects of e-business research, consideration of implications is the least often addressed. Because of the enormous import of information technology, Clarke (1988) issued a plea for implications to be researched in conjunction with at least applications of technology, and preferably right at the source, in the engineering, experimentation and trial usage phases. The intervening 13 years have seen the power of I.T. explode, the convergence of computing and communications completed, the convergence with content make great advances, location and tracking of devices and people become mainstream, and early steps taken towards the integration of robotics within I.T.

The need for social impact assessment is now seriously overdue, if errors yet worse than those of nuclear scientists and engineers of the first half of the twentieth century are to be avoided. Areas in especial need of attention include:

- workplace behaviour, stress, and skills formation;

- employment / income-distribution mechanisms;

- urban, regional, rural and remote accessibility and use;

- consumer and citizen behaviour;

- consumer and citizen rights;

- privacy (as distinct from mere security and data protection); and

- marketing, including permission-based, consensual, micro-, 1-to-1 and other forms of non-mass communications.

\section{CONCLUSIONS}

E-business research involves focusing a still-young discipline on a very young domain. The challenges of rapid change in technologies and behaviour, combined with inadequacies in research activities, are compounded by the confrontation between the academic demand for rigour and the real-world need for relevance.

It is easy to draw negative conclusions, such as that research will continue to be under-funded and inadequately performed, and that academics at the outset of their careers would be well-advised to choose less exciting domains in which to undergo their research training. 
Some positive conclusions are possible, however. e-business must be perceived as a research domain, and the mistake avoided of regarding it as a new discipline. It needs the insights and methods of established disciplines brought to bear on it. In many circumstances, it is essential that multiple disciplines be carefully integrated within a single research project. This is because existing theories are inadequate to provide a basis for describing, let alone understanding, and far less predicting, the behaviour of individuals, organisations and mechanisms such as e-communities, marketspaces and eenhanced societies.

The research methods devised to address particular research questions need to achieve both depth and breadth of understanding. In general, this requires either a compound technique such as case studies, or multiple complementary techniques, such as semi-structured interviews and surveys. Holistic approaches, and the integration of the insights of multiple disciplines, present special challenges, because they inevitably derive from distinct bodies of theory developed in order to describe rather different phenomena.

For real-world audiences to be attracted and informed, and for support to be gained from them, e-business research must be motivated by instrumentalism. Hence relevance needs to be regarded as the primary objective, and rigour as the constraint, rather than the other way around. This will create challenges for academics who need to achieve a modicum of publication in the highest-ranking and inevitably academically very demanding journals. It is therefore a responsibility of senior academics, who are less seriously impacted upon by the 'publish or perish' imperative, to devise, acquire funding for, and manage, e-business research programs.

Finally, the focus of research must not be limited to technology, applications of technology, and adoption of applications, but must also extend to their impact and their personal, legal, social and economic implications. Descriptive and explanatory outcomes must be complemented by predictive value, and must extend to normative outcomes, in order to inform the vital policy debates that surround e-business.

\section{REFERENCES}

A substantial list of references is provided at Clarke (2000a).

Alter S., Ein-Dor P., Markus M.L., Scott J. \& Vessey I. (2001) 'Does The Trend Toward EBusiness Call For Changes In The Fundamental Concepts Of Information Systems? A Debate' Commun. AIS 5, 10 (April 2001), at cais.isworld.org/articles/510/cais.isworld.org/articles/5-10/ 
Galliers, R.D. (1992) 'Choosing Information Systems Research Approaches', in Galliers R.D. (ed., 1992) 'Information Systems Research: Issues, Methods and Practical Guidelines', Blackwell, 1992. pp. 144-162

Keen P. (1980) 'MIS Research: Reference Disciplines and a Cumulative Tradition' McLean E. (Ed.), Proc. 1st Int'l Conf. Info. Sys. 1980, 9-18

Klein H.K. \& Lyytinen K. (1985) 'The Poverty of Scientism in Information Systems' in Mumford E., Hirschheim R., Fitzgerald G. \& Wood-Harper T. (Eds.) (1985) 'Research Methods in Information Systems' North-Holland, 1985, pp. 131-161

Kuhn T. (1962) 'The Structure of Scientific Revolutions' Uni. of Chicago Press, 1st Edition 1962, 2nd Edition 1970

Popper K.R. (1959) 'The Logic of Scientific Discovery', Basic Books, 1959

Popper K.R. (1968) 'Conjecture and Refutations' Harper \& Row, 1968

Zwass V. (1996) 'Electronic Commerce: Structures and Issues' Int'l J. Electronic Commerce 1,1 (Fall 1996) 3-23, at www.mhhe.com/business/mis/zwass/ecpaper.html 